\title{
ILLUMINANCE EVALUATION AND ASSESSMENT AT THREE ELEMENTARY SCHOOLS
}

\author{
${ }^{1}$ Ahmed Cherif Megri, ${ }^{2}$ Yao Yu, ${ }^{3}$ Akeel Sobers and ${ }^{3}$ Alyssa Cooper \\ ${ }^{1}$ Civil, Architectural and Environmental Engineering, CERT Research Center, \\ ${ }^{2}$ Department of Computational Science and Engineering, \\ ${ }^{3}$ Civil, Architectural and Environmental Engineering, \\ North Carolina A and T State University, Greensboro, North Carolina, USA
}

Received 2014-02-03; Revised 2014-03-14; Accepted 2014-03-27

\begin{abstract}
A simplified model for illuminance prediction has been developed to estimate the indoor level of lighting under artificial lighting. As well, illuminance in several locations of three schools has been measured under several conditions: Blinds up/lights on, blinds up/lights off, blinds down/lights on, blinds down/lights off. The experimental data of the case "blinds down/lights on" has been compared to the model developed and the results are very encouraging. The purpose of this study is to identify the level of illuminance in elementary schools classroom, to compare it to the IES requirements and the values predicted by the program developed. A parametric study has been performed to study the effect of the Light Loss Factor (LLF) and the luminous power on the lighting and energy performance of the illumination system.
\end{abstract}

Keywords: Illumination, Experimentation, Computer Program, Modeling, IES, Evaluation

\section{INTRODUCTION}

Lighting is one of the most important of all building systems, according to the National Lighting Bureau. Every school relies on lighting to provide an affective learning environment, which is one of the most critic physical characteristics of the classroom.

The modern elementary classrooms are spaces where multiple activities take place, where lighting quality and quantity are critical for students. The relationship between good lighting and students' performance has been demonstrated (Phillips, 1997; Hathaway and Fielder, 1986). Also, the quality of lighting (color rendering index, color temperature and lighting spectrum) can also impact the education process (Sinofsky and Knirck, 1981). Taylor and Gousie (1988) noted the ill effects of poor lighting on neuron doctrine functions, hyperactivity, health and on task behavior. Hathaway (1988) concluded that under full spectrum fluorescent lamps with ultraviolet enhancement, students developed fewer dental cavities and had better attendance achievement and growth and development than students under other light.

Understanding the relationship between light and the environment can help designers or architects to improve interior designs for better performance (Oneworkpalce, 1999). A comprehensive literature review about the influence of indoor lighting on people's productivity and performance especially students' learning performance has been performed (Samani and Samani, 2012).

In this study, a relatively simplified model for illuminance prediction, for both punctual and linear lighting sources, has been developed to estimate the indoor level of lighting under artificial lighting. As well, illuminance in several locations of three schools has been measured under several conditions: Blinds up/lights on, blinds up/lights off, blinds down/lights on, blinds down/lights off. The objective of measuring illuminance under these conditions is to separate the daylighting part from the total illuminance. The second purpose of this

Corresponding Author: Ahmed Cherif Megri, Civil, Architectural and Environmental Engineering, CERT Research Center, North Carolina A and T State University, Greensboro, North Carolina 
study is to identify the level of illuminance in elementary schools classroom, to compare it to the IES requirements and the values predicted by the program developed. A parametric study has been performed to study the effect of the Light Loss Factor (LLF) and the luminous power on the lighting and energy performance of the illumination system.

\section{ILLUMINATION MODEL FOR ARTIFICIAL LIGHTING}

A comprehensive model taking into account the factors that affect the building illuminance in building has been developed. This model includes both punctual and linear sources. Point calculation methods are used to predict the illuminance at specific locations. This information may be required to assure that sufficient illuminance has been provided at a specific point in the space and/or at work plan level and evaluate uniformity of illumination.

\subsection{Punctual Source}

The average illuminance produced by a lighting system is equal to the flux per area. To determine the iluminance required to produce specific illuminance at the level of work plane, the percentage of lamp lumens which actually reach that plane $(\mathrm{CU})$ must be considered into the calculation:

$$
\mathrm{E}_{\mathrm{Avg}}=\frac{\Phi * \mathrm{CU} * \mathrm{LLF}^{*} \mathrm{~N}_{\mathrm{F}}}{\mathrm{A}}
$$

Where:

$\mathrm{E}_{\mathrm{Avg}}=$ Average illuminance (lux or foot-candle)

$\mathrm{N}_{\mathrm{f}}=$ The number of luminaries

$\Phi=$ The initial luminous flux of the light source (lumen)

$\mathrm{CU}=$ The coefficient of utilization

$\mathrm{A}=$ Area to be illuminated $\left(\mathrm{m}^{2}\right)$

LLF $=$ The Light Loss Factor (Simons and Bean, 2001; Chen, 1999).

At any point at which the illuminance is to be calculated is not in a plan e normal to the source the flux spreads out to cover a wider area.

Illuminance can be calculated as at a specific point (point-by-point method), on a plane which is normal or not to the source, using the Equation 2. Consider a point source illuminating a surface at an angle $\theta$ to the normal.
$\mathrm{E}_{\mathrm{h}}=\frac{\mathrm{I} \cdot \operatorname{Cos}^{3} \theta}{\mathrm{H}^{2}}$

$\mathrm{H}=$ The height of fixture above a horizontal plane containing the point

$\mathrm{I}=$ The light intensity given, in candelas, for each angle $\theta$

This law assumes a point source: A source so infinitesimally small that it has no dimension (Lindsey, 1997). This equation prvides acceptable accuracy as long as the maximum luminous dimension of the source does not exceed $1 / 5$ th of the distance from the luminaire to the point at which the illuminance is to be calculated.

Linear lighting source: In case the source has a maximum dimension (Lindsey, 1997) that is greater than $1 / 5$ th the distance from the point at which the illuminance is to be calculated the source is arbitrary divided into several smaller sources so that each segment is less than 1/5th of the distance. The intensities at each angle from the photometric data for the fixture are determined. The illuminance produced by each section of the luminaire is estimated. The total illuminance includes the contribution of each section Equation 3:

$\mathrm{E}=\sum_{\mathrm{i}=1}^{\mathrm{n}} \mathrm{E}_{\mathrm{i}}$

$\rho_{\mathrm{r}}, \rho_{\mathrm{f}}, \rho_{\mathrm{w}}$ are estimated knowing the walls, floor and roof colors Equation 4 and 5.

\subsection{Roof Effective Reflectance}

$$
\begin{gathered}
\rho_{\text {roof eff }}=\frac{A_{r} \cdot \rho_{r}+A_{w} \cdot \rho_{w}}{A_{r}+A_{w}} \\
\rho_{\text {fioor eff }}=\frac{A_{r} \cdot \rho_{f}+A_{w} \cdot \rho_{w}}{A_{f}+A_{w}}
\end{gathered}
$$

Reflectance are available from manufacturers of paints and furniture finishing as shown in Table 1.

Typical recommends in offices are shown in Table 2.

\subsection{Regression to Estimate the Coefficient of Utilization}

$$
\mathrm{CU}=\mathrm{f}\left(\rho_{\text {roof eff }}, \rho_{\mathrm{w}}, \mathrm{RCR}\right)
$$

The CU of a fixture is specified to that fixture and varies as a function of three factors (Lindsey, 1997): 
Table 1. Reflectance of surfaces as provided from manufacturers

\begin{tabular}{ll}
\hline Color & $\begin{array}{l}\text { Reflectance } \\
(\rho)(\%)\end{array}$ \\
\hline White, off-white, light shades of gray, brown, blue & $75-90$ \\
Medium green, yellow, brown or gray & $30-60$ \\
Dark gray, medium blue & $10-20$ \\
Dark blue, green, wood paneling & $5-10$ \\
\hline
\end{tabular}

Table 2. Typical recommended reflectance in offices

\begin{tabular}{ll}
\hline & Light $(\%)$ \\
\hline Celling & $70-90$ \\
Wall & $50-70$ \\
Floor & $20-50$ \\
\hline
\end{tabular}

the physical characteristics of the luminaire, the room dimensions and the percentage of light which is reflected by room surfaces (the ceiling color, the wall color and the floor color). Basically, $\mathrm{CU}$ is the ratio of the total flux received by surface to the total lamp flux of the installation. To estimate the CU value, Lindsey (1997) model has been used Equation 6-12:

$$
\begin{aligned}
& \mathrm{CU}=\frac{2 \cdot 5 \rho_{1} \mathrm{C}_{3}\left(1-\mathrm{D}_{\mathrm{G}}\right) \Phi_{\mathrm{D}}}{\mathrm{G}\left(1-\rho_{1}\right) \cdot\left(1-\rho_{3}\right) \mathrm{C}_{0}}+\frac{\rho_{2} \mathrm{C}_{2} \mathrm{C}_{3} \Phi_{\mathrm{U}}}{\left(1-\rho_{2}\right) \cdot\left(1-\rho_{3}\right) \mathrm{C}_{0}} \\
& +\left[1-\frac{\rho_{3} \mathrm{C}_{3}\left(\mathrm{C}_{1}+\mathrm{C}_{2}\right)}{\left(1-\rho_{3}\right) \mathrm{C}_{0}}\right] \cdot \frac{\mathrm{D}_{\mathrm{G}} \Phi_{\mathrm{D}}}{1-\rho_{3}} \\
& \mathrm{C}_{1}=\frac{\left(1-\rho_{1}\right) \cdot\left(1-\mathrm{f}_{2 \rightarrow 3}^{2}\right) \cdot \mathrm{G}}{2.5 \rho_{1}\left(1-\mathrm{f}_{2 \rightarrow 3}^{2}\right)+\mathrm{G}_{2 \rightarrow 3}\left(1-\rho_{1}\right)} \\
& \mathrm{C}_{2}=\frac{\left(1-\rho_{2}\right) \cdot\left(1+\mathrm{f}_{2 \rightarrow 3}\right)}{1+\rho_{2} \cdot \mathrm{f}_{2 \rightarrow 3}} \\
& \mathrm{C}_{3}=\frac{\left(1-\rho_{3}\right) \cdot\left(1+\mathrm{f}_{2 \rightarrow 3}\right)}{1+\rho_{3} \cdot \mathrm{f}_{2 \rightarrow 3}} \mathrm{C}_{0}=\mathrm{C}_{1}+\mathrm{C}_{2}+\mathrm{C}_{3} \\
& \mathrm{D}_{\mathrm{G}}=\frac{1}{\Phi_{\mathrm{D}} \Phi_{\mathrm{T}}} \sum_{\mathrm{N}=1}^{9}\left(\mathrm{~K}_{\mathrm{GN}} \Phi_{\mathrm{N}}\right) \mathrm{K}_{\mathrm{GN}}=\mathrm{e}^{\left(-\mathrm{AG} \mathrm{G}^{\mathrm{B}}\right)} \\
& \Phi_{\mathrm{D}}=\frac{1}{\Phi_{\mathrm{T}}} \sum_{\mathrm{N}=1}^{9} \Phi_{\mathrm{N}} \\
& \Phi_{\mathrm{U}}=\frac{1}{\Phi_{\mathrm{T}}} \sum_{\mathrm{N}=1}^{18} \Phi_{\mathrm{N}} \\
& \mathrm{f}_{2 \rightarrow 3}=0.026+0.503 \mathrm{e}^{(-0.270 \cdot R C R)}+0.470 \mathrm{e}^{(-0.119 \cdot R \mathrm{RCR})}
\end{aligned}
$$

Where:
$\Phi_{\mathrm{D}}=$ Fractional downward flux

$\Phi_{\mathrm{T}} \quad=$ Total lamp lumens

$\mathrm{G}=$ The room cavity ratio

$\mathrm{K}_{\mathrm{GN}}=$ The zonal multiplier

$\mathrm{G}=$ The room cavity ratio

$\mathrm{N}$ = The zone for which the multiplier is being calculated.

Values for A and B are found in the IES Lighting Handbook, 1983 Reference Volume.

\section{ILLUMINATION BUILDING DESIGN}

The design concerns the creation of a new product (in our case the product is a building or one of its components, mechanical or electrical system). For safety and economic reasons, the designer needs to take into account the requirements of multiple standards and codes, such as the ICC codes, IES standards, NEC code and ASHRAE standards. Among ASHRAE standards, the designer needs to satisfy ASHRAE 55-2010, ASHRAE 62-2010 and ASHRAE 90.1-2013.

In the case of building illumination, the design process start with gathering data related to the building and rooms dimensions (length, width and height), the considered color of the walls, ceiling and floor. The height of the fixtures (for recessed fixture, the height is zero). The IES recommended light levels (Table 3). The estimation of the number of fixtures and their locations is then calculated (Table 4).

In the design process, the number of fixtures $\mathrm{N}_{\mathrm{f}}$ (Equation 1) is estimated based on IES requirement, work area, Coefficient of Utilization (CU), the amount of light produced by each lamp (lumens) and many other coefficients, such as:

Table 3. IES illuminance recommendations (recommended light levels)

\begin{tabular}{ll}
\hline Task area & Illuminance (fc) \\
\hline Corridors/Stairways/Restrooms & $10-20$ \\
Storage Rooms & $10-50$ \\
Conference Rooms & $20-50$ \\
General Offices & $50-100$ \\
Drafting/Accounting & $100-200$ \\
Areas with VDTs & 75 \\
Classrooms & $50-75$ \\
Cafeterias & 50 \\
Gymnasiums & $30-50$ \\
Merchandising & $30-150$ \\
Manufacturing Assembly & $50-500$ \\
Parking Areas (uncovered) & $2-1$ \\
\hline
\end{tabular}


Ahmed Cherif Megri et al. / American Journal of Engineering and Applied Sciences 7 (1): 129-136, 2014

Table 4. Rooms dimensions and lighting characteristics of the schools tested

\begin{tabular}{|c|c|c|c|c|c|c|c|c|c|c|c|c|}
\hline & & Area & Length & Width & Height & $\begin{array}{l}\text { Wall } \\
\text { color }\end{array}$ & $\begin{array}{l}\text { Ceiling } \\
\text { color }\end{array}$ & $\begin{array}{l}\text { Floor } \\
\text { color }\end{array}$ & $\begin{array}{l}\text { Floor } \\
\text { type }\end{array}$ & Fixtures & $\begin{array}{l}\text { Working } \\
\text { lamps }\end{array}$ & $\begin{array}{l}\text { Lamps in } \\
\text { fixture }\end{array}$ \\
\hline \multirow[t]{6}{*}{ School 1} & Room 1 & 816.60 & 27.30 & 34.00 & 9.0 & White & White & Dark blue & Carpet & 16 & 57 & 4 \\
\hline & Room 2 & 1062.00 & 30.00 & 25.40 & 9.0 & White & White & Dark blue & Carpet & 16 & 61 & 4 \\
\hline & Room 3 & 1087.50 & 30.00 & 36.30 & 9.0 & White & White & Dark blue & Carpet & 16 & 62 & 4 \\
\hline & Room 4 & 1087.50 & 30.00 & 36.30 & 9.0 & White & White & Dark blue & Carpet & 16 & 58 & 4 \\
\hline & Room 5 & 1015.00 & 29.00 & 25.00 & 9.0 & White & White & Dark blue & Carpet & 16 & 57 & 4 \\
\hline & Room avg & 1013.72 & 29.26 & 31.40 & 9.0 & White & White & Dark blue & Carpet & 16 & 59 & 4 \\
\hline \multirow[t]{6}{*}{ School 2} & Room 1 & 857.70 & 31.00 & 27.70 & 9.0 & Tan & White & Tan & Tile & 16 & 45 & 2 \\
\hline & Room 2 & 857.70 & 31.00 & 27.70 & 10.5 & Tan & White & Tan & Tile & 23 & 46 & 2 \\
\hline & Room 3 & 857.70 & 31.00 & 27.70 & 10.5 & Tan & White & Tan & Tile & 23 & 45 & 2 \\
\hline & Room 4 & 857.70 & 31.00 & 27.70 & 10.5 & Tan & White & Tan & Tile & 23 & 39 & 2 \\
\hline & Room 5 & 535.60 & 19.40 & 27.60 & 10.5 & Tan & White & Grey & Tile & 18 & 33 & 2 \\
\hline & Room avg & 793.28 & 28.68 & 27.68 & 10.5 & Tan & White & Tan & Tile & 22 & 42 & 2 \\
\hline \multirow[t]{6}{*}{ School 3} & Room 1 & 903.50 & 30.30 & 29.80 & 9.0 & White & White & Dark blue & Carpet & 16 & 58 & 4 \\
\hline & Room 2 & 903.50 & 30.30 & 29.80 & 9.0 & White & White & Dark blue & Carpet & 16 & 59 & 4 \\
\hline & Room 3 & 903.50 & 30.30 & 29.80 & 9.0 & White & White & Dark blue & Carpet & 16 & 58 & 4 \\
\hline & Room 4 & 903.50 & 30.30 & 29.80 & 9.0 & White & White & Dark blue & Carpet & 16 & 60 & 4 \\
\hline & Room 5 & 903.50 & 30.30 & 29.80 & 9.0 & White & White & Dark blue & Carpet & 16 & 63 & 4 \\
\hline & Room avg & 903.50 & 30.30 & 29.80 & 9.0 & White & White & Dark blue & Carpet & 16 & 60 & 4 \\
\hline
\end{tabular}

- LOF: Lamp operating factor (a multiplier to modify the lumens output of each lamp under filed conditions)

- LLD: Lamp lumen depreciation

- LDD: Luminaire dirt depreciation (Equation 13):

LOF $=$ VF.TF.BF.PF

- VF: Voltage factor

- TF: Temperature factor

- BF: Ballast factor

- PF: Position tilt factor (for HID lamps only)

The accurate estimation of these coefficients is essential for an accurate estimation. This depends on many factors, like understanding the type of lamps/luminaires used (operation factor, lumen depreciation, ballast factor) the type of maintenance, the type of environment designed (dirt depreciation).

The objective of this project is to perform illuminance measurements and compare the actual illuminance in classrooms to the IES requirements. The measurements are taken from three elementary schools located in Greensboro (NC). The measurements are compared to the values obtained from the developed model and also to the IES standard for classrooms.

The IES standards illumination at the level of the desktops (the amount of light that should reach the desktops) of classrooms is 50-75 foot-candles (fc). Since the standard does not differentiate between the amounts of light that need to reach the desks for elementary schools compared to high schools and college classrooms, we will take the mean of the IES standard and average it with the base number. This should account for the difference in height between the desks in elementary schools to all others. The average considered is $57 \mathrm{fc}$. Any number considered between 50 and $75 \mathrm{fc}$ is acceptable. The hypothesis for this project is that the schools as well as the simulated classrooms will all comply with the IES standards.

The procedure for the experiment is to first take the dimensions of the room (length, width and height) to calculate the area and cavity ratios. The wall color, floor color and floor type are also recorded. The next step is to then estimate the ceiling, floor and room cavity ratios for each classroom. The information regarding the lamps and fixtures used in the rooms need to be found. In particular, the type and amount of fixtures, the number, type and characteristics of the lamps used in the fixtures are needed. Once all of these basic observations about the room are found, then the measuring of the footcandles on the work plane may begin. The illuminance in each room was measured in five different locations throughout the work plane under four different conditions. These conditions were the blinds drawn and lights on, blinds shut and lights on, blinds drawn and lights off and blinds shut and lights off (Fig. 1-4). In Fig. 3 (artificial lighting only), a comparison between the model and the measurement has been performed and a good agreement is noticed. The Fig. 6 and 7 demonstrate the parametric study, where the effect of LLF and the luminous flux on the lighting density is shown. 


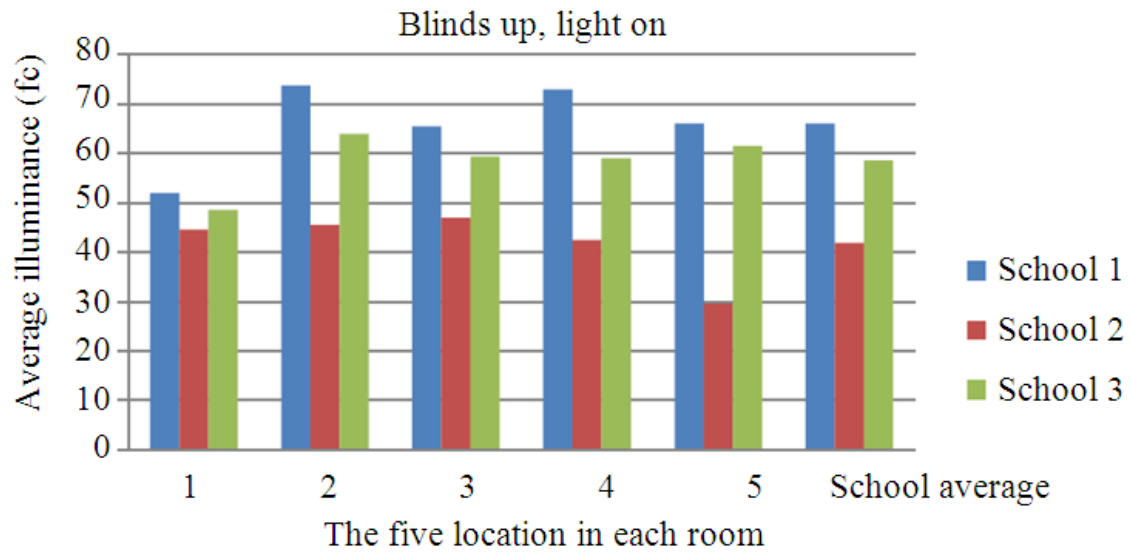

Fig. 1. Illuminance (fc) comparison between schools (blinds up, lights on)

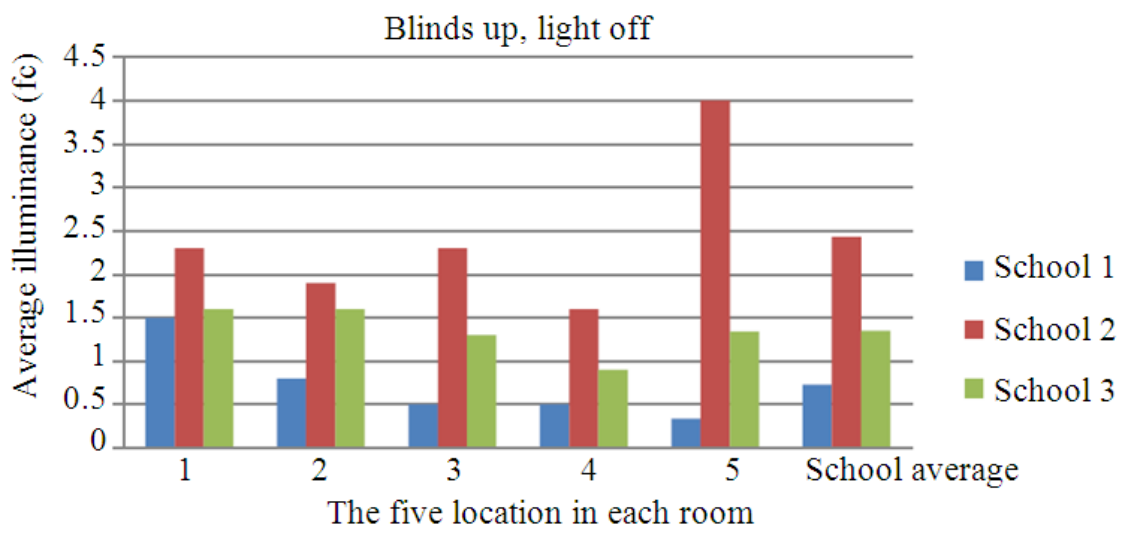

Fig. 2. Illuminance (fc) comparison between schools (blinds up, lights off)

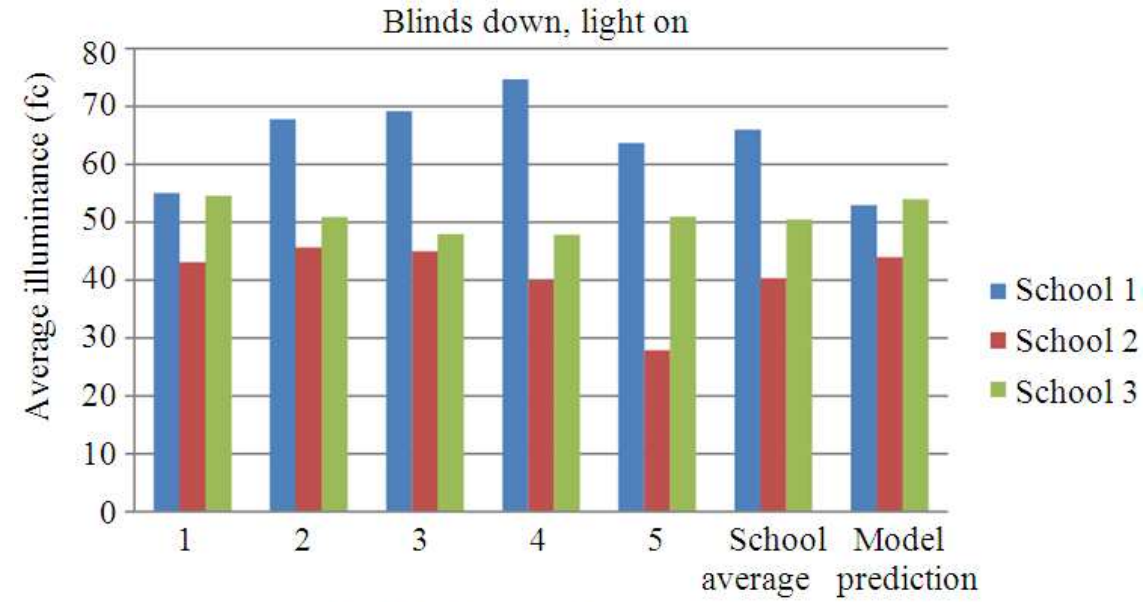

The five location in each room

Fig. 3. Illuminance (fc) comparison between schools (blinds down, lights on) 
Ahmed Cherif Megri et al. / American Journal of Engineering and Applied Sciences 7 (1): 129-136, 2014

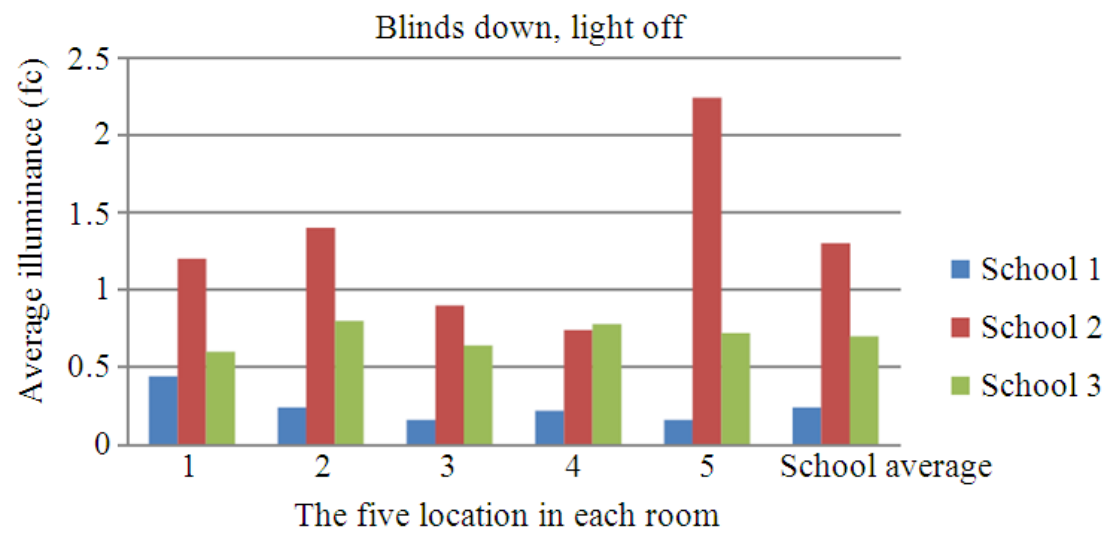

Fig. 4. Illuminance (fc) comparison between schools (blinds down, lights off)

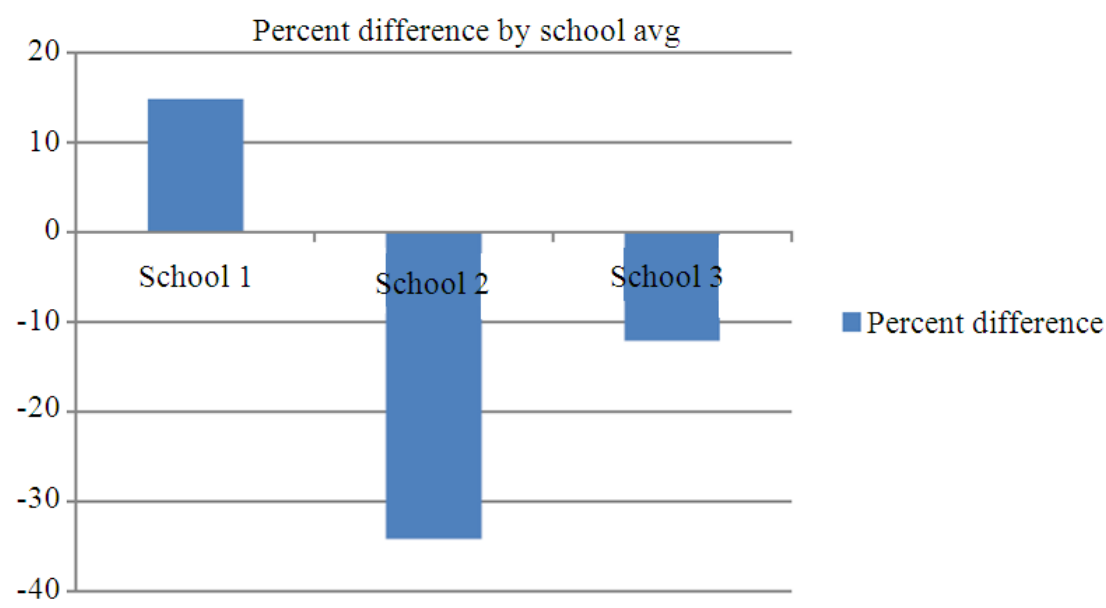

Fig. 5. Percent difference by school average illuminance

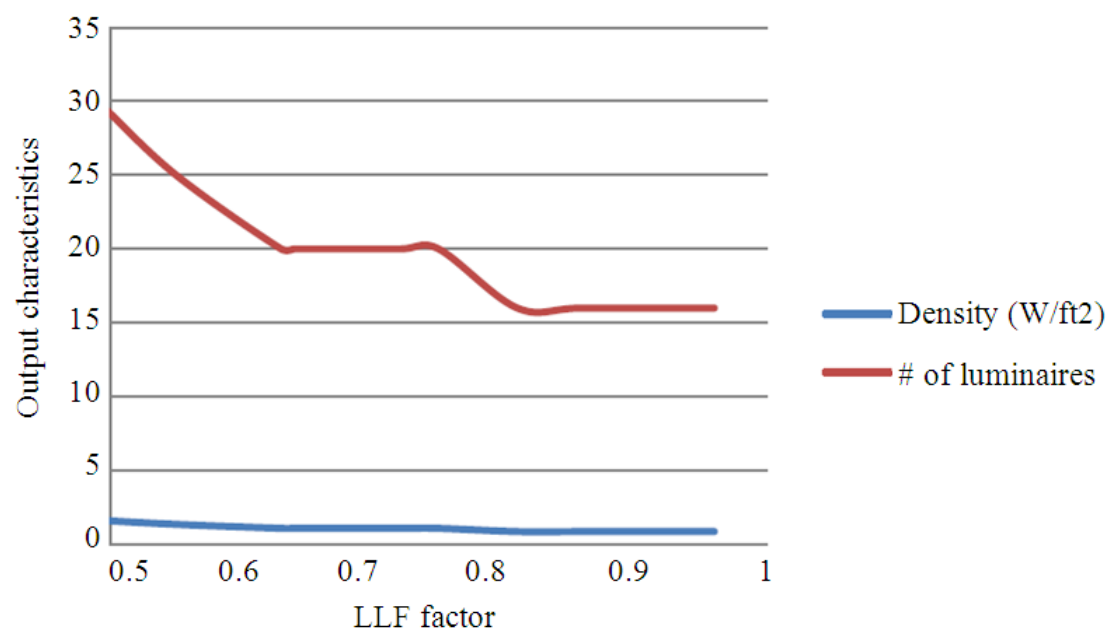

Fig. 6. Effect of Light Loss Factor (LLF) on lighting performance 


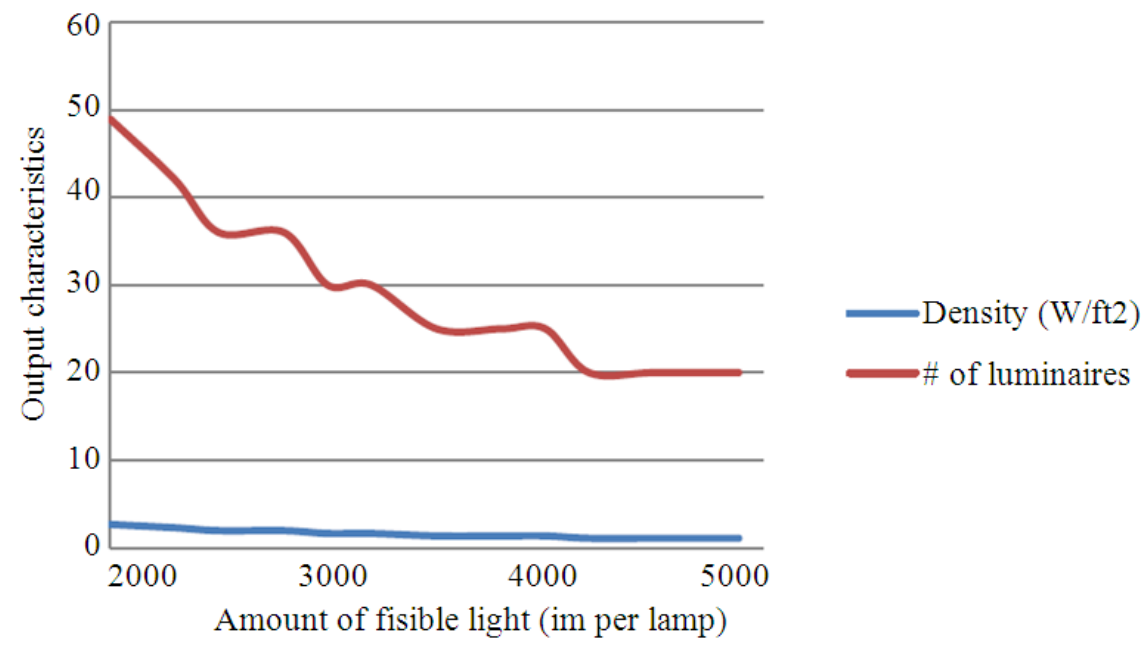

Fig. 7. Effect of amount of visible lighting on lighting performance

Data Analysis: The averages of the illuminance measured in the classrooms are compared to the IES average that was decided in the hypothesis of $62 \mathrm{fc}$. Afterwards, the percent difference formula was used to calculate the differences in the room and school averages to our IES average. We need to point out that even though a room might appear to be failing the IES standards, any average in the percentage difference formula can drop to $-13 \%$ and still comply with the actual IES standards (Fig. 5):

$$
\text { Percent Difference }=\frac{\mathrm{E}_{\mathrm{Mea}, \text { avg }}-\mathrm{E}_{\mathrm{IES}, \mathrm{Avg}}}{\left(\mathrm{E}_{\mathrm{Mea}, \text { avg }}+\mathrm{E}_{\mathrm{IES}, \text { Avg }}\right) / 2} * 100
$$

The absolute values of the percent difference formula was intentionally omitted to show either the excess or lack of light to the work plane.

\section{DISCUSSION}

Within this project alone, there were a lot of variances that could be minimized, but not completely removed from the data. For example, the time of day, daylight and the weather conditions and the amount of light transmitted through the windows are all variable that can only be controlled to some degree during the project. Options to minimize the false readings of the light reflected is to take the foot-candle reading for the lights off and blinds up and subtract it from the reading from the lights on and the blinds up. With this, the light reflected by the windows can be somewhat removed and not considered as a contributing factor in the lighting.
Another variance in the project is the amount of lamps that were burn out during the data collection process. In every classroom, there were at least two burns out lamps that could have easily lowered the amount of foot-candles that reached the work plane. If those lamps were operational, the readings for some of the lower foot-candle classrooms would have risen by at least $2 \mathrm{fc}$ and probably more depending on the amount of lamps were replaced.

Yet another variance in this project, is the amount of posters, cupboards, doors, etc. that cover a moderate percentage of the wall. Depending on the material and color of the items on the wall, the amount of reflected light reaching the work plane is severely reduced because of the amount of light absorbed by the items on the wall.

In conclusion, three elementary schools were measured to find the amount of light reached the work plane when compared to the recommended IES standards. Out of these three schools, schools one and three met the actual IES standards given, while only school one met the IES average that was assumed for elementary schools.

\section{CONCLUSION}

A simplified model for illuminance prediction has been developed to estimate the indoor level of lighting under electrical lighting. The objective of this model is to predict the point by point level of lighting, as well as the average illuminance. In order to validate our model, the illuminance in several locations of three elementary schools has been measured under different conditions: 
Blinds up/lights on, blinds up/lights off, blinds down/lights on, blinds down/lights off, to separate the daylighting part from the total illuminance. The experimental data of the case "blinds down/lights on" has been compared to the model developed and the results are in very good agreement. The purpose of this study is to identify the level of illuminance in elementary schools classroom, to compare it to the IES requirements and the values predicted by the program developed. A parametric study has been performed to identify the effect of the Light Loss Factor (LLF) and the luminous flux on the lighting and energy performance of the illumination system.

\section{REFERENCES}

Chen, K., 1999. Energy Management in Illuminating Systems. 1st Edn., CRC press, Boca Raton, USA, ISBN-10: 0849326281, pp: 176.

Hathaway, W.E. and D.R. Fielder, 1986. A window on the future: A view of education and educational facilities. Council of Educational Facility Planners, International, Columbus, Ohio.
Hathaway, W.E., 1988. Educational facilities: Neutral with respect to learning and human performance. CEFPI J., 26: 8-12.

Lindsey, 1997. Applied Illumination Engineering. 2nd Edn., The Fairmont Press, Inc., Lilburn, Ga., ISBN10: 0881732125, pp: 516.

Oneworkpalce, 1999. Seeing the difference, the importance of quality lighting in the workplace.

Phillips, R.W., 1997. Educational Facility Age and the Academic Achievement and Attendance of Upper Elementary School Students. 1st Edn., University of Georgia, pp: 178.

Samani, S.A. and S.A. Samani, 2012. The impact of indoor lighting on students' learning performance in learning environments: A knowledge internalization perspective. Int. J. Bus. Scoial Sci.

Simons, R.H. and A.R. Bean, 2001. Lighting Engineering. Architectural Press.

Sinofsky, E.R. and F.G. Knirck, 1981. Choose the right color for your learning style. Instructional Innovator, 26: 17-19.

Taylor, A. and G. Gousie, 1988. The ecology of learning environments for children. CEFPI J., 26: 23-28. 